\title{
Piaget's Egocentrism and Language Learning: Language Egocentrism (LE) and Language Differentiation (LD)
}

\author{
JeongChul Heo \\ University of Nevada, Reno, USA \\ Sumi Han \\ Seoul Cyber University, South Korea \\ Christopher Koch \\ University of Nevada, Reno, USA \\ Hasan Aydin \\ University of Nevada, Reno, USA \\ Email: aydinh@unr.edu
}

\begin{abstract}
Piaget's theory, which is at the center of cognitive approach and major theoretical foundation in terms of the intelligent development, explains children's language learning by using four stages of cognitive development. For instance, Piaget maintains that Egocentrism is related to language learning as an inner speech and can affect on differentiation in cognitive development. This paper is to focus on the important educational foundation and information, which can prove how Language Egocentrism (LE) and Language Differentiation (LD) have an influence on native and second language acquisition for young children (two to seven years old), and what characteristics can be included in the subcategories of LE and LD.
\end{abstract}

Index Terms-Language Egocentrism (LE), Language Differentiation (LD), language learning mechanics, second language acquisition, Piaget

\section{INTRODUCTION}

A cognitive approach to learning and human development emphasizes on mental or internal factors as contrasted with environmental or external factors as many traditional behaviorists. Thinking involves successive adaptation of assimilation and accommodation to an environment and results in the organization of the mental structure or schemata. The interaction of assimilation and accommodation in the process of attaining equilibrium accounts for cognitive development from birth to death (Schiamberg, 1985).

Much of Piaget's works has aided educators in understanding children's cognitive development. His theories in terms of a cognitive realm have greatly influenced on understanding of factors in language learning. In addition, many language theories demonstrate that Egocentrism is the meaningful element relevant to language learning as an inner speech and can impact differentiation in the cognitive development (Mitchell \& Myles, 2004; Wadsworth, 1996).

Diverse theories in language learning have been studied through a variety of perspectives such as social factors, social-interaction, psychological elements, cognitive development, age, gender, and so on (Brown, 2000; Cook, 2007; Mitchell \& Myles, 2004). Smith (as cited in Mitchell \& Myles, 2004) also mentions that some aspects of language might be genetically controlled and related to deficit in cognitive development such as Specific Language Impairment (SLI). For these reasons, many studies and theories that are related to native language learning and second language acquisition have shown that it is very critical to understand significant elements in multiple and diverse perspectives, not in a single factor.

This paper is to focus on the important educational foundation and information that can prove how Language Egocentrism (LE) and Language Differentiation (LD) can affect the native language learning and second language acquisition for young children (2-7 years old), and what characteristics can be included in the sub categories of LE and LD. Furthermore, LE and LD can be reviewed by multiple inner factors such as personality, learning pattern, and inner characteristics.

\section{PIAGET's BASIC CONCEPT}

\section{A. Schema}


Piaget uses the word, schema. Schemata (i.e., the plural of schema) are the cognitive or mental structures by which individuals adapt to and organize their environments. Wadsworth (1996) explains that when a child is born, he or she has few schemata and develops his/her schemata gradually, and then it becomes more generalized, differentiated, and "adult". However, Wadsworth (1996) argues that schemata do not have physical counterparts and are not observable. They are inferred to exist and are called as the hypothetical constructs.

\section{B. Adaptation}

Assimilation and accommodation are two sides of adaptation. Boeree (2006) describes that assimilation and accommodation work like pendulum swings by advancing our understanding on the world and our competency in them. $\mathrm{He}$ also emphasizes that the assimilation is the cognitive process by which a person integrates new perceptual or conceptual information into existing schemata or patterns of behaviors. Furthermore, he suggests that assimilation theoretically does not result in a change of schemata, but it does influence on the growth of schemata and is a part of development.

On the other hand, the accommodation is the creation of new schemata or the modification of old schemata. This process of accommodation is a schema-building or schema-modifying process. It is the process of modifying an action to fit into a new object (Solso, 1995). An infant sucks on a nipple but has to adjust its sucking action in order to drink from a cup. Wadsworth (1996) suggests that once accommodation has taken place, a child can try again to assimilate the stimulus because the structure has changed.

\section{Process of Intellectual Organization}

When a child realizes differences between new and old schema, he/she loses balance or equilibrium because new concept does exist in his/her schema (Small, 1990). For example, in a little Suzy story, Suzy realizes that a two-wheeled bike is different from the tricycle. She must work to accommodate the new bicycle information by constructing a new schema for bicycle. She can assimilate the new information into her newly constructed bicycle schema. Once Suzy has constructed new schema and assimilated bicycle riding into it, she has attained balance and is once again in equilibrium.

\section{Stage OF Cognitive DeVElopment}

\section{A. Sensorimotor Stage (Birth-2 Years Old)}

As the name implies, the infant in a sensorimotor stage uses senses and motor abilities to understand the world (Hughes, 2001). A baby may suck their thumb. That feels good, so he/she sucks some more. The infant's behavior is largely reflexive and undifferentiated. These basic reflexes with the infant are sucking, grasping, crying, and moving his/her arms, trunk, and head. The more sophisticated sucking schema exists when permitting differentiation (Huitt \& Hummel, 2003). In addition, a child begins the transition between the sensorimotor level of intelligence and representational intelligence in the sensorimotor stage (Kodat, 2002). Representation allows a child to find objects that are hidden by invisible displacement. Around one and a half, a child is clearly developing the mental representation that is the ability to hold an image in his/her mind. Two years after birth, the child is beginning to talk (i.e., symbolic representation), has clearly evolved intellectual operations, and is beginning to think (Wadsworth, 1996).

\section{B. Preoperational Stage (2-7 Years Old)}

During preoperational development intelligence, a child evolves from a sensorimotor intelligence to a representational intelligence. In this stage, the child is able to use symbols and language. A drawing, a written word, or a spoken word comes to understand in order to represent a real object. Along with symbolization, there is a clear understanding of past and future. In this stage, obstacles to logical thought are egocentrism, transformational reasoning, reversibility, and conservation (Taylor, 1996). Egocentrism can make different forms at different levels of development, but is always characterized by a lack of differentiation in their thoughts (Doran \& Cowan, 1975). Another characteristic of preoperational child's thinking is his/her inability to reason successfully about transformations. The child in the preoperational stage is not able to mentally reverse mentally the act of lengthening (Brown, 2000).

\section{Concrete Operations Stage (7-11 Years Old)}

In this stage, children not only can use symbols, but also can manipulate these symbols logically to solve problems. By six or seven years old, most children develop the ability to conserve number, length and liquid volume. Conservation means that a quantity remains the same despite changes in appearance of objects. In addition, a child learns classification and seriation during this stage (Hughes, 2001). Classification and seriation are important logics to solve the basic arithmetic in a school. The concrete operations stage can be viewed as a transition between pre-logical thought and complete logical thought of older children who have attained formal operations stage.

\section{Formal Operations Stage (11 Years Old and Up)}

In this stage, a child constructs the reasoning and logics to solve all problems (Huitt \& Hummel, 2003). Concrete operational children have difficulties in reasoning on complex verbal problems such as propositions, hypothetical problems, or the future. Formal operations are characterized by scientific reasoning and hypothetical reasoning, and reflect a highly developed understanding of causation. On the other hand, formal operations stage is not accomplished 
by all children (Kodat, 2002). For instance, several studies have concluded that no more than half the American population develops all the possibilities of formal operations (Kohlberg, 1981). Furthermore, data from adolescent populations presented that only 30 to $35 \%$ of high school seniors approach the formal operations stage (as cited in Huitt \& Hummel, 2003).

For this paper, authors will focus on young children who are aged from two to seven years old and in their preoperational stage.

\section{EGOCENTRISM AND LANGUAGE LEARNING}

\section{A. Egocentrism in Piaget's Cognitive Development}

Egocentrism can take different forms at different levels of development, but is always characterized by a lack of differentiation in thoughts (Wadsworth, 1996). Therefore, young children take into account discrepancies between their own knowledge and information of peers in their early cognitive development.

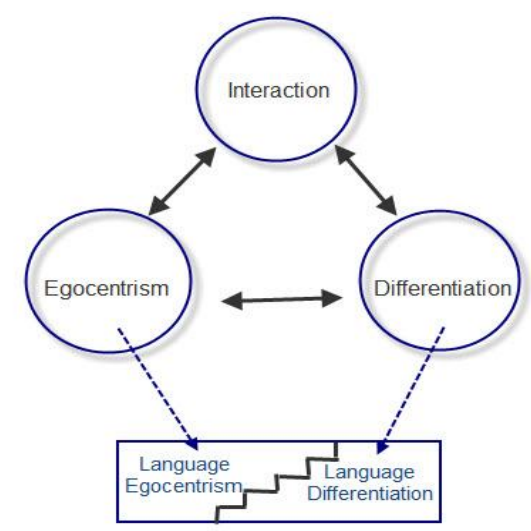

Figure 1. Relationship between Egocentrism and Differentiation

For instance, Wadsworth (1996) holds that the sensorimotor child is initially egocentric in that he/she lacks differentiation between the self as an object and other objects. It has shown that the preoperational child initially is unable to differentiate between thoughts of others and his/her own thoughts. In figure 1, egocentrism, differentiation, and interaction are closely related, and these egocentric thoughts of children in a preoperational stage would be diminishing with augment of interaction and cognitivity, while differential thought is rising in concrete and formal stages of children.

Doran and Cowan (1975) suggest that a measure of peer interaction is not correlated with any of several measures of egocentrism (e.g., spatial egocentrism, communication egocentrism, or role taking skill) and conclude that egocentrism is not a unitary variable, while Piaget (as cited in Doran \& Cowan, 1975) suggests that one of the most important environmental factors leading to the diminishing of egocentrism is related to the interaction of a child with his/her peers. In addition, Deutsch (1974) finds a relationship between peer interaction and communication egocentrism in preschool children.

Essentially, Egocentrism can be viewed as an internal learning mechanism, and it has a much more central role to play in learning language with a variety of interactions (Egocentrism, 2009; Schwartz, Maynard, \& Uzelac, 2008). In addition, a child with a high level of logical thoughts or differentiation does not mean that he/she would use a low egocentrism in his/her language learning. The egocentrism in language learning does not mean that it is a reverse proportional to the level of differentiation, and does not have any advanced stages such as a Piaget's cognitive development. In other words, egocentrism or differentiation can be viewed as a dominant learning tendency (or learning mechanism) for students in language learning and second language acquisition.

\section{B. Language Egocentrism (LE) and Language Differentiation (LD)}

Wadsworth (1996) maintains that early preoperational thought is dominated by presence or absence of Piaget's concepts: egocentrism, reservation, transformation, and reversibility. In addition, obstacles to logical thoughts are egocentrism, transformations, centration, and reversibility (Wadsworth, 1996). Meanwhile, the competence of egocentrism in this preoperational stage can permit a child to absorb information, knowledge or language around him/her.

Rycek, Stuhr, McDermott, Benker, and Swartz (1998) find that females have higher levels of egocentrism than do males in their adolescent research. Many substantial researchers present higher verbal ability in normally achieving females and higher visual-spatial and mathematical abilities in normally achieving males (Hyde, Fennema \& Lamon, 
1990; Vogel, 1990). Younger children and females can get higher level of egocentrism with dominant learning mechanism of LE when compared with adults and males who possess higher level of reasoning in language learning. Therefore, LE can be referred to as a critical innate learning tendency and mechanism belonging to Egocentrism that helps children in their language learning.

In figure 2, it can be critical to define and analyze important elements of LE based on a wide variety of research related to Piaget's Egocentrism in language learning, and then these elements can be used to explain the definition of LE in the area of the first and second language acquisition. The dichotomous factors of LE and LD also can have influence on the learning of nature and second language, and can be viewed as a dominant or inferior tendency in the area of language learning. Whereas, Piaget's theory explains that the degree of Egocentrism is reversely proportional to a development of reasoning for children. As a result, LE and LD co-exist and interact in the same inner realm as a dominant or inferior tendency.

The concept of LE is based on diverse inner elements that are representative for young children's characteristics in language learning. Furthermore, LE can be related more closely to initial learning tendency or pattern in a language learning and acquisition, in which a child would use a private speech, imitation, and modeling to learn a language (Tucker, 2003). In contrast, LD can be related to diverse learning tendencies such as language ego, reasoning, and interaction, which students acquire in a cognitive development and maturity.

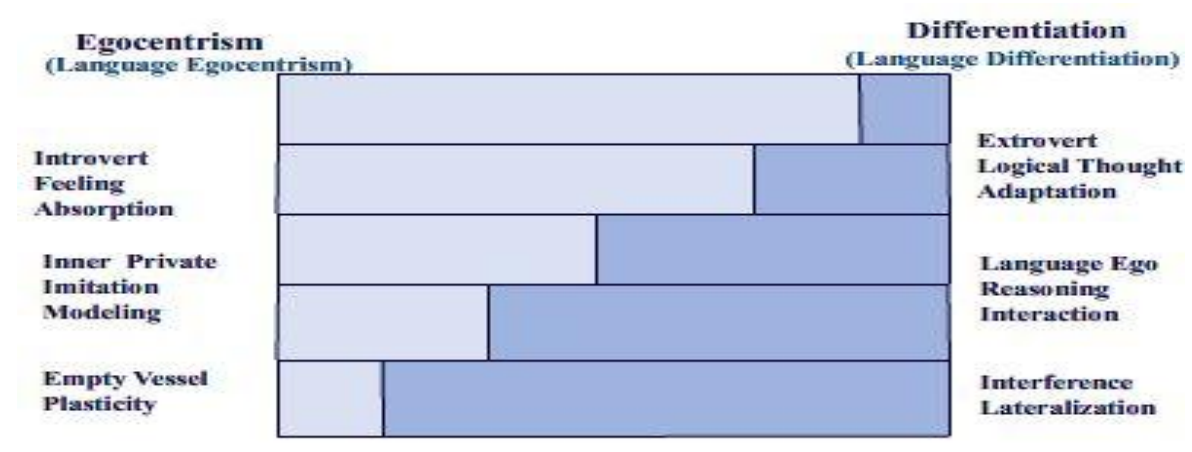

Degree of Language Egocentrism vs. Language Differentiation

as tendency in language learning

Figure 2. LE versus LD

In figure 2, young children and adolescents hold both LE and LD in language learning tendency (Barr \& Keysar, 2004). They can construct dominant tendencies from multiple sub-areas of LE and LD, and the degree of dominant tendencies can be affected by multiple inner factors such as age, gender, and personality. For example, adolescent egocentrism can be explained by multiple dimensions, not by a single perspective (Muuss, 1982; Schwartz, Maynard \& Uzelac, 2008). Therefore, it is necessary to explain LE with sub- categories in order to observe diverse dimensions in terms of Egocentrism. This paper explains that LE and LD could include three sub categories: Personality, Learning Pattern, and Inner Characteristics.

\section{Perspective of Personality}

Brown (2000) maintains that if we were to devise theories on second language acquisition or teaching methodologies that are based only on cognitive considerations, we would be omitting the most fundamental side of human behavior. He also explains that systematic study for the role of personality in second language acquisition has already led to the greater understanding of the language learning process and to improved language teaching designs.

Cook (2007) also explains that some researchers have investigated the familiar division between extrovert and introvert personalities that could have an influence on language learning in terms of learning style preference. For instance, a child who tends to use LE might be related to introvert characteristics using feeling and absorption in affective concepts. On the other hand, a child who has a tendency of LD might be classified as an extrovert tendency student using logical thought and adaptation in his/her language learning.

LE can be an initial booster in language learning and language acquisition for young children when compared with LD. In addition, a child, who uses LE more than LD, tends to use feeling and absorption with sticking to his/her introvert tendency in language learning. On the other hand, a child who has tendency for LD is likely to use logical thoughts and adaption. As a result, the first sub category of LE versus LD can be explained by affective and logical perspectives that are based on the innate domain in a dichotomous style. For example, a child with dominant tendency of LE presents stronger introvert feeling and absorption than extrovert energy, logical thought, and adaptation in terms of sub-categories of personality.

\section{Perspective of Learning Pattern}

Children in the concrete/operations stage are expected to apply logical learning patterns by developing reasoning and 
social interaction. Meanwhile, there might be deteriorating primitive learning methods (or talents), such as absorption, imitation, and modeling because they apply more logical methods because of deterioration of Egocentrism. In this period, diverse learning patterns of LE and LD can coexist in children's learning.

Piaget (as cited in Doran \& Cowan, 1975) presents that young children are well known to engage in a private speech, and this speech has been interpreted as an evidence for children's egocentrism. Furthermore, Vygotsky (as cited in Mitchell \& Myles, 2004) explains that private speech eventually becomes inner speech with a use of language to regulate internal thoughts. In addition, Solso (1995) explains that Piaget believed that a child uses egocentric speech with self-centered tendency and Vygotsky suggested that Egocentric speech of children seems to be a result of external interaction.

On the other hand, learning patterns related to LD can increasingly affect and interrupt students' language learning. For instance, Brown (2000) explains that 'language ego' means a self-esteem that maintains walls of inhibition to protect a weak or fragile ego, or a lack of self-confidence. Guiora, Beit-Hallami, Brannon, Dull, and Scovel (as cited in Brown, 2000) conclude that less defensive or adaptive language ego promotes the pronunciation ability in a second language in Thai. In other words, learning patterns of LD can also make a negative role as interference relevant to a language ego when adults learn their second languages.

As a result, learning patterns can be changed and complicated with deterioration of egocentrism and augment of differentiation. Moreover, the dominant tendency of LE pattern means that children and adolescents are likely to be familiar with primitive learning methods such as private speech, imitation, and modeling with low language ego.

\section{E. Perspective of Inner Characteristics}

Tucker (2003) holds that cognitive development of adults hinders second language learning, and leads to a tendency to overanalyze. Cook (2007) also suggests that the apparent decline of adults' language learning is connected with physical factors such as the loss of plasticity in a brain and lateralization of a brain. Therefore, these different emotional and physical changes can make adults unable to regain the egocentric elements of their childhood.

In the education ideology, intellectual factors of children are considered by cultural transmission and academic rationalism that view children as "empty vessels" (Dello' Olio \& Donk, 2007; Kohlberg, 1981). In the dominant tendency of LE, inner characteristics of empty vessels imply that there is an inner status of plasticity with absence of interference related to logical thoughts. On the contrary, dominant tendency of differentiation on inner characteristics means that children and adolescents lose "plasticity" in the brain with strong interference related to logical thoughts and abstract mode of thinking.

In summary, it is very crucial concept that language-learning tendencies can be demonstrated by dichotomous elements of LE and LD in the three sub-categories that can affect tendencies of language learning. In addition, different lines of figure 2 between LE and LD represent that dominant tendency of language learning between LE and LD can be changeable according to diverse elements in three subcategories and multiple perspectives such as age, gender, personality, and educational status (Muuss, 1982; Peterson \& Roscoe, 1991; Rycek et al., 1998; Schwatz et al., 2008). In addition, Rycek et al. (1998) explain that the level of egocentrism which is inversely proportional to reasoning should be changeable and should not be fixed by cognitive stages even in the post formal stage of adolescent in their adolescent egocentrism research. In other words, dominant tendencies between LE and LD can be changeable and co-existed.

\section{F. Role of LE and LD in Language Learning Stages}
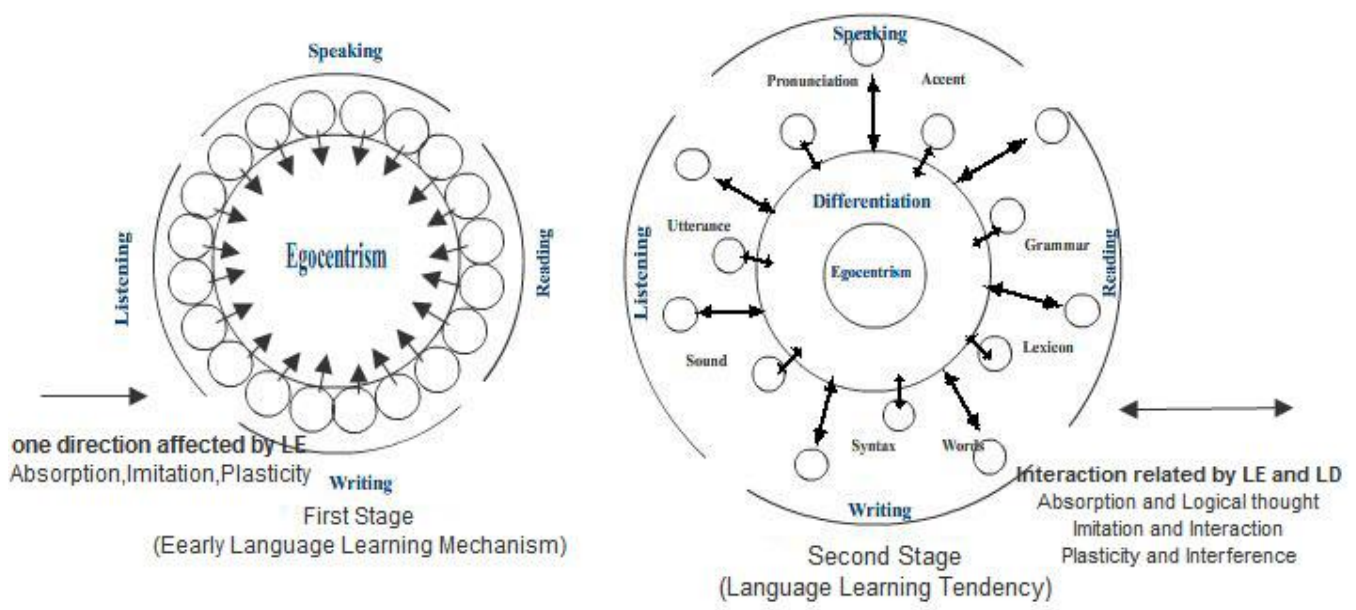

Figure 3. Language Egocentrism Stages

Figure 3 shows that there are two stages for LE status; the early language learning mechanism and language learning tendency. The first stage is similar to the Piaget's preoperational stage since young children are perfectly affected by LE without characteristics of LD or with a little amount of interference of it. A child in this stage is very egocentric and 
affected by elements of language egocentrism such as introvert energy, absorption, imitation, and plasticity.

In the first stage, the LE is a core that has no interference related to logical thoughts and language ego. Therefore, LE in the first stage can be considered to have one direction that can make young children absorb language as a sponge with characteristics of imitation and plasticity, and direct absorption of language.

While the first stage of early language learning mechanism can be explained in the preoperational stage of Piaget's theory, the second stage of language learning tendency can be related to the concrete and formal stages (Atherton, 2005). Children in the concrete and formal operations stages can make critical interaction between LE and LD. Children might build up their own language tendencies affected by LE and LD. For example, a child who presents a dominant tendency of LE is likely to use a private speech with interaction of low interference of language ego in language pattern. In other words, children in the stage of language learning tendency would not directly acquire language, but are in a status that has a dynamic interaction related to LE and LD.

As a result, it is concluded that effective learning mechanisms can be connected with learning mechanisms of young children who use dominantly characteristics of LE in early language mechanism. For example, Barr and Keysar (2004) conclude that language users are very egocentric and use egocentric ways in their language-learning environments.

In the second stage of language learning tendency, critical interferences of LD can slow down language acquisition to children with dominant tendency of LD because they can play a role as walls to interfere directly absorbing language and acquiring second language.

These facts can indicate that a language-learning environment will be more relevant to egocentric cognition and tendency than logical structure. LE can be considered to have a positive influence on language learning to children in dominant or second tendency with interaction affected by LE and LD.

\section{IMPLICATIONS}

Piaget's theory describes cognitive structures and language learning in terms of four stages of cognitive development. In the second preoperational stage, a child is egocentric in that he/she lacks differentiation between the self as an object and other objects. In the concrete operational stage and formal operations stage, a child can develop his/her logical thoughts, and keep developing higher levels of logical thinking and reasoning with deteriorating Egocentrism. In the language learning, Piaget (as cited in Doran \& Cowan, 1975) suggests that Egocentrism affects language learning for young children, and is an early learning mechanism related to inner or private speech to regulate internal thoughts. Egocentrism is likely to be a critical booster for the early language learning and is critical factor in the cognitive development with differentiation.

In the Piaget's theory, Egocentrism can be explained as a critical obstacle that hinders children's logical thoughts. Piaget suggests that Egocentrism is related to language learning as an inner speech (Mitchell \& Myles, 2004; Wadsworth, 1996). In addition, diverse theories in language learning have continued to be studied through a wild variety of perspectives including Egocentrism (Barr \& Keysar, 2004; Brown, 2000; Cook, 2007; Mitchell \& Myles, 2004). Therefore, language-learning tendencies between LE and LD can be referred to as a critical multiple- mechanism to understand children's language learning.

This paper puts a critical emphasis on the fact that dominant tendencies of language learning between LE and LD can be changeable and flexible in terms of age, gender, personality, and encounter of new knowledge. For example, reemergence and enhancement of egocentrism during the college experience can be an effective inner mechanism that let them adjust to a new educational environment, and achieve a variety of academic knowledge.

Finally, it is required to study the more effective learning methods such as how to improve LE as an early language mechanism, and how to reduce interferences related to logical thoughts and language ego. Therefore, children might be able to enhance tendencies of LE by exhilarating elements of LE such as absorption, inner private, imitation, and plasticity in a language learning.

\section{REFERENCES}

[1] Atherton, J. (2005). Piaget. Retrieved October 2, 2008 from http://www.learningandteaching.info/learning/piaget.html

[2] Barr, D. J., \& Keysar, B. (2004). Making sense of how we make sense: The paradox of egocentrism in language use. In H. L. Closton, \& A.N. Katz (Eds.), Figurative language comprehension. (pp. 21-42). NY: Lawrence Erlbaum.

[3] Boeree, C. G. (2006). Jean Piaget. Retrieved October 2, 2008 from http://webspace.ship.edu/cgboer/piaget.html

[4] Brown, H. D. (2000). Principles of language learning and teaching (4th ed.). New York: Addison Wesley Longman.

[5] Cook, V. (2007). Second language learning and language teaching (3rd ed.). New York: Oxford University Press.

[6] Dell' Olio, J.M., \& Donk, T. (2007). Models of teaching. Newbury Park, CA: Sage.

[7] Deutsch, F. (1974). Observational and sociometric measures of peer popularity and their relationship to egocentric communication in female preschoolers. Developmental Psychology, 10, 745-747.

[8] Doran, F., \& Cowan, P. A. (1975). Egocentrism and peer interaction: Testing Piaget's hypothesis. Retrieved January 31, 2009 from http://www.eric.ed.gov/ERICDocs/data/ericdocs2sq1/content_storage_01/0000019b/80/31/67/fb.pdf

[9] Egocentrism (n.d.). Retrieved from January 1, 2009 from http://en.wikipedia.org/wiki/Egocentrism

[10] Hughes, S. (2001). Jean Piaget's educational theory. Retrieved. October 4, 2008, from http://www.newfoundations.com/GALLERY/Piaget.html

[11] Huitt, W., \& Hummel, J. (2003). Piaget's theory of cognitive development. Retrieved October 2, 2008, from 
http://chiron.valdosta.edu/whuitt/col/cogsys/piaget.html

[12] Hyde, J.S., Fennema, E., \& Lamon, S. J. (1990). Gender differences in mathematics performance: A meta-analysis. Psychological Bulletin, 107(2), 139-155.

[13] Kodat, R. (2002). Jean Piaget's theory of cognitive development. Retrieved October 3, 2008 from http://www.esortment.com/all/jeanpiagettheo_rnrn.htm

[14] Kohlberg, L. (1981). Essays on moral development. New York: Harper \& Row.

[15] Mitchell, R., \& Myles, F. (2004). Second language theories (2nd ed.). New York: Hodder Arnold Publication.

[16] Muuss, R. E. (1982). Social cognition: David Ekind's theory of adolescent egocentrism. Adolescence, 17(66), 249-265.

[17] Peterson, K. L., \& Roscoe, B. (1991). Imaginary audience behavior in older adolescent females. Adolescence, 26(101), 195-200.

[18] Rycek, R. F., Stuhr, S. L., McDermott, J., Benker, J., \& Swartz, M.D. (1998). Adolescent egocentrism and cognitive functioning during late adolescence. Adolescence, 33(132), 745-749.

[19] Schiamberg, L. B. (1985). Human development. New York: Macmillan.

[20] Schwartz, P. D., Maynard, A. M., \& Uzelac, S. M (2008). Adolescent egocentrism: A contemporary view. Adolescence, 43(171), 441-448.

[21] Small, M. Y. (1990). Cognitive development. Orlando, FL: Harcourt Brace Jovanovich.

[22] Solso, R. L. (1995). Cognitive psychology (4th ed.). Boston: Allyn and Bacon.

[23] Taylor, J. (1996). Piagetian perspectives on understanding children's understanding. Childhood education, 72(5), $258-259$.

[24] Tucker, M. (2003). First and second language acquisition. Retrieved January 1,2009 from http://secrendip.brynmawr.edu/biology/b103/f03/web2/mtucker.html

[25] Vogel, S. A. (1990). Gender differences in intelligence, language, visual motor abilities, and academic achievement in students with learning disabilities. Journal of Learning Disabilities, 23(1), 44-52.

[26] Wadsworth, B. J. (1996). Piaget's theory of cognitive and affective development (5th ed.). New York: Longman Publisher.

JeongChul Heo, M.Ed., is a doctoral candidate in Information Technology at the University of Nevada Reno, USA. He completed his Master of Education in Counseling Psychology from the HongIk University in Korea. His main research areas include distance education, cognitive psychology, and cyber-counseling.

Sumi Han, Ph.D., is a professor in the Counseling Psychology Department at the Seoul Cyber University. She received her doctoral degree in Counseling and Educational Psychology at the University of Nevada, Reno, USA. Her main research areas are counseling for college students, cybercounseling, online education and learning.

Christopher Koch, MA, MSW, is a Ph.D. candidate in Teaching English Speakers to Other Languages (TESOL) at University of Nevada, Reno. His research area is Second Language Acquisition, and Applied linguistics.

Hasan Aydin, MA, is a Ph.D. candidate in Curriculum, Teaching, and Learning at University of Nevada, Reno, USA. He received his BA with distinction, in 2005 from the National University of Mongolia Department of Foreign Language Education where he specialized in Teaching English Overseas. In 2006 he began graduate studies at the University of Nevada, Reno (UNR), where he has completed a Master of Arts in Teaching English to Speakers of Other Languages (MA-TESOL with honorary). He is currently working as a Research Assistant and a PhD candidate in Curriculum, Teaching, and Learning at UNR, specializing in multicultural education. His research areas are cultural assimilation of Turkish immigrants in Romania and the United States, the Gülen Movement and Gülen-inspired schools in Nigeria. 